\title{
EFEKTIVITAS VEGETASI SEBAGAI PENJERAP TOTAL SUSPENDED PARTICULATE (TSP) DI KAWASAN SD NEGERI 24 PONTIANAK UTARA
}

\author{
Rurika Widya Ningrum Palureng ${ }^{1)}$, Dian Rahayu Jati(1), Sarma Siahaan ${ }^{2)}$ \\ 1)Program Studi Teknik Lingkungan Jurusan Teknik SIpil Fakultas Teknik Universitas Tanjungpura, Pontianak \\ 2)Program Studi Kehutanan Fakultas Kehutanan Universitas Tanjungpura, Pontianak \\ Email: rwidya.palureng@gmail.com
}

\begin{abstract}
ABSTRAK
Kondisi sekolah yang berada di tepi jalan mengakibatkan kemungkinan adanya kontaminasi udara dengan polutan yang berasal dari kendaraan bermotor. Apabila polusi udara terjadi di lingkungan sekolah, maka hal ini akan dapat memberikan dampak yang signifikan terhadap penyakit pernafasan pada anak. Salah satu pencemar udara adalah Total Suspended Particulate (TSP). Cara yang dapat dilakukan agar kualitas lingkungan udara menjadi lebih baik adalah dengan adanya vegetasi di lingkungan sekolah karena vegetasi dapat menjerap TSP yang ada di udara. Penelitian ini dilakukan untuk mengetahui efektivitas vegetasi yang ada di lingkungan SD Negeri 24 Pontianak Utara yaitu tanaman pucuk merah dan ketapang dalam menjerap TSP. Penelitian ini dilakukan dengan mengukur konsentrasi TSP dengan menggunakan High Volume Air Sampler (HVAS) serta dilakukan perhitungan volume kendaraan dan volume kerimbunan daun. Nilai konsentrasi tertinggi selama penelitian tergolong berada diatas baku mutu PP RI Nomor 41 Tahun 1999 yaitu sebesar $104,7644 \mu \mathrm{g} / \mathrm{Nm}^{3}$. Berdasarkan hasil penelitian didapatkan bahwa tanaman ketapang memiliki efektivitas yang lebih besar dibandingkan dengan efektivitas pada tanaman pucuk merah. Efektivitas terbesar terjadi pada siang hari dimana tanaman ketapang memiliki efektivitas sebesar $53,37 \%$, sedangkan tanaman pucuk merah hanya sebesar $22,41 \%$. Tanaman ketapang memiliki kemampuan yang lebih baik dalam menjerap TSP disebabkan karena volume kerimbunan daun yang dimiliki tanaman ketapang lebih besar yaitu 155,83 $\mathrm{m}^{3}$ dibandingkan dengan tanaman pucuk merah hanya $2,56 \mathrm{~m}^{3}$. Selain itu tanaman ketapang memiliki bentuk daun yang lebih lebar serta memiliki batang yang lebih besar bila dibandingkan dengan tanaman pucuk merah.
\end{abstract}

Kata Kunci : Pucuk Merah, Ketapang, Total Suspended Particulate (TSP), SD Negeri 24 Pontianak Utara

ABSTRACT

The condition of roadside schools poses the possibility of air contamination by pollutants coming from motor vehicles. Air pollution that occurs in the school environment may have significant impact on respiratory diseases in children. One of air pollutants is Total Suspended Particulate (TSP). Measure that can be taken to improve the environmental quality of the air is by holding vegetation in school environment since vegetations are able to adsorb TSP in the air. This research was conducted to determine the effectiveness of the existing vegetation in Public Elementary School No. 24 North Pontianak, namely Syzygium oleana and Terminalia catappa in absorbing the TSP. This research was conducted by measuring the concentration of TSP by using High Volume Air Sampler (HVAS) as well as calculating vehicle volume and leaf volume. The highest concentration value during the study was above the standard according to Government Regulation of Republic Indonesia Number 41 Year 1999 which is amounted to 104,7644 $\mu \mathrm{g} / \mathrm{Nm}^{3}$. Based on the results of the research, it was found that Terminalia catappa plants have greater effectiveness compared to the effectiveness of Syzygium oleana in adsorbing the TSP. The greatest effectiveness occurs during the day where Terminalia catappa plants have an effectiveness of 53.37\%, while Syzygium oleana only amounted to $22.41 \%$. Terminalia catappa plants have a better ability to adsorb TSP because the leaf volume owned by Terminalia catappa have a greater value amounted to $155.83 \mathrm{~m}^{3}$ compared with Syzygium oleana which is only amounted to $2.56 \mathrm{~m}^{3}$. In addition, Terminalia catappa plants have a wider leaf shape and has a larger stem compared with Syzygium oleana.

Keywords: Syzygium oleana, Terminalia catappa, Total Suspended Particulate (TSP), Public Elementary School No. 24 North Pontianak 


\section{PENDAHULUAN}

Kemajuan peradaban telah menggeser perkembangan ke berbagai bidang termasuk penggunaan alat-alat transportasi. Hal ini berdampak pada timbulnya berbagai masalah lingkungan salah satunya adalah pencemaran udara. Salah satu pencemar udara berbahaya yang sering ditemukan adalah TSP atau Total Suspended Particulate. Masalah polusi yang disebabkan oleh TSP merupakan masalah yang berbahaya bagi kehidupan manusia baik yang beraktivitas di dalam maupun di luar ruangan. TSP telah memicu berbagai penyakit seperti infeksi pernafasan dan juga gangguan pada penglihatan.

Sekolah memiliki lingkungan yang dipengaruhi banyak faktor. Apabila polusi udara terjadi di lingkungan sekolah, maka hal ini akan dapat memberikan dampak yang signifikan terhadap penyakit pernafasan pada anak (Wiraadiputri, 2012). SD Negeri 24 Pontianak Utara merupakan salah satu sekolah dasar yang terletak di Jalan Khatulistiwa, Siantan Hilir, Pontianak Utara, Kota Pontianak, Kalimantan Barat. Kondisi sekolah yang berada di tepi jalan (berada 2 meter setelah jalan raya) mengakibatkan kemungkinan adanya kontaminasi udara dengan polutan yang berasal dari kendaraan bermotor. Kondisi ini dikhawatirkan akan memberikan dampak berupa kualitas udara yang kurang baik nantinya dimana kualitas udara yang kurang baik ini akan dapat mengganggu kesehatan warga sekolah, terutama untuk para siswa yang masih tergolong anak-anak.

Salah satu cara yang dapat dilakukan agar kualitas lingkungan udara menjadi lebih baik adalah dengan adanya vegetasi di lingkungan sekolah. Hal ini diyakini mampu menekan polusi udara, tidak terkecuali TSP. SD Negeri 24 Pontianak Utara memiliki beberapa vegetasi di lingkungan sekolahnya. Dengan adanya vegetasi di lingkungan sekolah ini maka polutan udara di lingkungan sekolah akan berkurang dan kualitas udara akan menjadi lebih baik. Namun tidak semua vegetasi dapat menjadi biofilter TSP yang baik. Masing-masing vegetasi memiliki kemampuan yang berbeda-beda dalam menyerap TSP di udara. Oleh karena itu, dilakukanlah penelitian ini untuk mengetahui efektivitas vegetasi di lingkungan sekolah yaitu SD negeri 24 Pontianak Utara sebagai penjerap pencemar udara yaitu TSP. Hasil penelitian ini diharapkan akan dapat memberi rekomendasi serta referensi agar nantinya dapat menjaga dan memperbaiki kualitas udara di sekitar lingkungan sekolah demi mendukung kelangsungan kegiatan belajar mengajar.

\section{METODOLOGI PENELITIAN}

Penelitian dilaksanakan di SD Negeri 24 Pontianak Utara yang berlokasi di Jalan Khatulistiwa, Kelurahan Siantan Hilir, Kecamatan Pontianak Utara, Kota Pontianak, Kalimantan Barat. Pengambilan sampel dilakukan selama 1 minggu pada tanggal 9-15 Agustus 2017 dan dilakukan pengulangan pada minggu berikutnya yaitu tanggal 16-22 Agustus 2017. Pengukuran dilakukan pada 3 waktu dalam sehari yaitu pagi hari pada pukul 06.00-08.00 WIB, siang hari pada pukul 12.00-14.00 WIB, dan sore hari pada 16.00-18.00 WIB.

Penelitian dilakukan dengan melakukan pengukuran konsentrasi TSP dengan menggunakan alat High Volume Air Sampler (HVAS). Selain itu dilakukan penghitungan volume kendaraan bermotor yang melintas selama waktu pengukuran dan faktor 
meteorologis meliputi suhu udara, kelembaban udara, kecepatan angin dan arah angin dengan menggunakan Pocket Weather Meter.

Pengambilan data primer ini dilakukan di 3 titik yang telah dipertimbangkan. Titik pertama terletak di Jalan Khatulistiwa tepatnya di seberang SD Negeri 24 Pontianak Utara. Titik ini dijadikan sebagai titik kontrol karena pada titik tersebut tidak terdapat vegetasi sehingga dapat diketahui konsentrasi TSP udara apabila tidak terdapat vegetasi. Titik kedua dilakukan pada tanaman Ketapang dan titik ketiga dilakukan pada tanaman Pucuk Merah. Diambil data parameter vegetasi pada kedua tanaman tersebut yang meliputi jenis (nama lokal dan nama ilmiah vegetasi), tinggi pohon, diameter tajuk, bentuk kanopi, dan volume kerimbunan. Pengumpulan data vegetasi ini untuk mengetahui volume kerimbunan daun (Resiana, 2014). Alat HVAS diletakkan dibelakang vegetasi tersebut dengan jarak 3 meter dari sumber emisi (jalan raya). Layout penelitian adalah seperti dibawah ini:

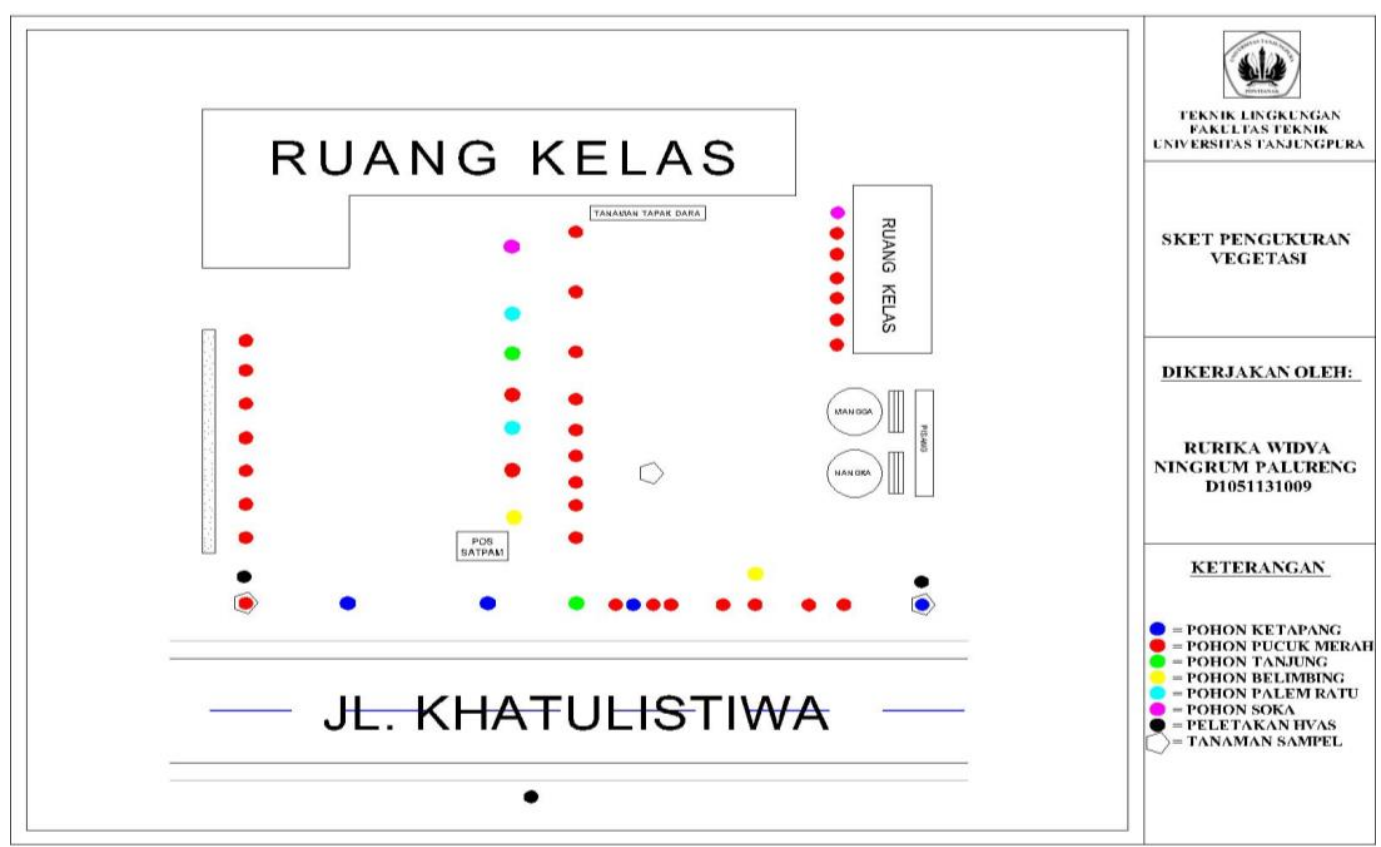

Gambar 1. Layout Lokasi Pengukuran

\section{HASIL DAN PEMBAHASAN}

A. HASIL PENGUKURAN PENGUKURAN VOLUME KENDARAAN, FAKTOR METEOROLOGIS, DAN KONSENTRASI TOTAL SUSPENDED PARTICULATE (TSP) PADA TITIK KONTROL

Tabel 1. Volume kendaraan, faktor meteorologis, dan konsentrasi TSP pukul $06.00-08.00$ WIB

\begin{tabular}{cccccc}
\hline \multirow{2}{*}{$\begin{array}{c}\text { Volume } \\
\text { Kendaraan }\end{array}$} & $\begin{array}{c}\text { Suhu } \\
\left({ }^{\circ} \mathrm{C}\right)\end{array}$ & $\begin{array}{c}\text { Kelembaban } \\
(\%)\end{array}$ & $\begin{array}{c}\text { Kecepatan } \\
\text { Angin } \\
(\mathrm{m} / \mathrm{s})\end{array}$ & $\begin{array}{c}\text { Arah } \\
\text { Angin }\end{array}$ & $\begin{array}{c}\text { Konsentrasi TSP } \\
\left(\mu \mathrm{\mu g} / \mathrm{Nm}^{3}\right)\end{array}$ \\
\hline 10721 & 26,99 & 84,83 & 1,40 & $\mathrm{~W}$ & 78.5805 \\
\hline 10560 & 26,46 & 85,59 & 1,19 & $\mathrm{~N}$ & 76.5821 \\
\hline 10733 & 25,89 & 86,25 & 0,98 & $\mathrm{~N}$ & 72.7039 \\
\hline 9058 & 25,96 & 86,34 & 1,43 & $\mathrm{NW}$ & 57.8069 \\
\hline
\end{tabular}




\begin{tabular}{cccccc}
\hline \multirow{2}{*}{$\begin{array}{c}\text { Volume } \\
\text { Kendaraan }\end{array}$} & $\begin{array}{c}\text { Suhu } \\
\left({ }^{\circ} \mathrm{C}\right)\end{array}$ & $\begin{array}{c}\text { Kelembaban } \\
(\%)\end{array}$ & $\begin{array}{c}\text { Kecepatan } \\
\text { Angin } \\
(\mathrm{m} / \mathrm{s})\end{array}$ & $\begin{array}{c}\text { Arah } \\
\text { Angin }\end{array}$ & $\begin{array}{c}\text { Konsentrasi TSP } \\
\left(\mu \mathrm{g} / \mathrm{Nm}^{3}\right)\end{array}$ \\
\hline 4598 & 26,09 & 87,25 & 0,74 & $\mathrm{~S}$ & 37.2893 \\
\hline 10857 & 26,78 & 86,08 & 0,95 & $\mathrm{~N}$ & 78.5338 \\
\hline 10953 & 26,89 & 86,36 & 0,99 & $\mathrm{NW}$ & 82.2993 \\
\hline 10880 & 26,69 & 85,80 & 1,13 & $\mathrm{~W}$ & 80.3646 \\
\hline 10714 & 27,01 & 84,99 & 1,23 & $\mathrm{~N}$ & 82.3453 \\
\hline 10983 & 26,90 & 85,14 & 1,56 & $\mathrm{~N}$ & 87.9229 \\
\hline 9567 & 25,91 & 87,44 & 0,81 & $\mathrm{~S}$ & 65.2265 \\
\hline 4353 & 26,26 & 86,98 & 1,05 & $\mathrm{~N}$ & 33.6012 \\
\hline 10781 & 27,73 & 87,06 & 0,98 & $\mathrm{NW}$ & 84.4033 \\
\hline 10855 & 27,93 & 86,39 & 0,86 & $\mathrm{NW}$ & 84.4572 \\
\hline
\end{tabular}

Tabel diatas merupakan tabel pengukuran pada pagi hari yaitu pukul 06.00-08.00 WIB. Berdasarkan tabel tersebut didapatkan hasil bahwa volume kendaraan terbanyak terjadi pada tanggal 18 Agustus 2017 sedangkan yang volume kendaraan paling sedikit terjadi pada tanggal 20 Agustus 2017. Begitu juga dengan konsentrasi TSP yang didapatkan. Konsentrasi tertinggi terjadi pada tanggal 18 Agustus 2017, sedangkan konsentrasi terendah terjadi pada tanggal 20 Agustus 2017.

Tabel 2. Volume kendaraan, faktor meteorologis, dan konsentrasi TSP pukul $12.00-14.00 \mathrm{WIB}$

\begin{tabular}{cccccc}
\hline \multirow{2}{*}{$\begin{array}{c}\text { Volume } \\
\text { Kendaraan }\end{array}$} & $\begin{array}{c}\text { Suhu } \\
\left({ }^{\circ} \mathrm{C}\right)\end{array}$ & $\begin{array}{c}\text { Kelembaban } \\
(\%)\end{array}$ & $\begin{array}{c}\text { Kecepatan } \\
\text { Angin } \\
(\mathbf{m} / \mathbf{s})\end{array}$ & Arah Angin & $\begin{array}{c}\text { Konsentrasi TSP } \\
\left(\boldsymbol{\mu g} / \mathbf{N m}^{3}\right)\end{array}$ \\
\hline 6552 & 34,46 & 68,86 & 1,44 & $\mathrm{~W}$ & 90.0798 \\
\hline 6184 & 31,94 & 71,64 & 1,11 & $\mathrm{SW}$ & 81.7746 \\
\hline 7143 & 34,49 & 67,51 & 1,30 & $\mathrm{SW}$ & 93.9692 \\
\hline 7456 & 33,34 & 68,60 & 2,55 & $\mathrm{~S}$ & 97.4364 \\
\hline 8312 & 31,25 & 68,38 & 1,26 & $\mathrm{~W}$ & 92.9816 \\
\hline 7464 & 33,51 & 67,66 & 1,01 & $\mathrm{~S}$ & 95.5789 \\
\hline 0 & 0 & 0 & 0 & - & 0 \\
\hline 6407 & 32,61 & 67,23 & 1,03 & $\mathrm{SW}$ & 87.6744 \\
\hline 6357 & 33,64 & 66,38 & 1,51 & $\mathrm{~W}$ & 87.9698 \\
\hline 6607 & 32,83 & 66,25 & 1,64 & $\mathrm{~W}$ & 89.6495 \\
\hline 7487 & 32,09 & 67,26 & 1,31 & $\mathrm{~S}$ & 93.1915 \\
\hline 8341 & 32,36 & 71,86 & 1,44 & $\mathrm{~S}$ & 104.7644 \\
\hline 7537 & 32,95 & 66,75 & 1,01 & $\mathrm{SW}$ & 97.3303 \\
\hline 7570 & 33,25 & 67,11 & 1,33 & $\mathrm{~S}$ & 103.1213 \\
\hline
\end{tabular}


Tabel diatas merupakan tabel pengukuran pada siang hari yaitu pukul 12.00-14.00 WIB. Berdasarkan tabel tersebut didapatkan hasil bahwa volume kendaraan terbanyak terjadi pada tanggal 20 Agustus 2017 sedangkan yang volume kendaraan paling sedikit terjadi pada tanggal 10 Agustus 2017. Begitu juga dengan konsentrasi TSP yang didapatkan. Konsentrasi tertinggi terjadi pada tanggal 20 Agustus 2017, sedangkan konsentrasi terendah terjadi pada tanggal 10 Agustus 2017.

Tabel 3. Volume kendaraan, faktor meteorologis, dan konsentrasi TSP pukul 16.00-18.00 WIB

\begin{tabular}{cccccc}
\hline \multirow{2}{*}{$\begin{array}{c}\text { Volume } \\
\text { Kendaraan }\end{array}$} & $\begin{array}{c}\text { Suhu } \\
\left({ }^{\circ} \mathrm{C}\right)\end{array}$ & $\begin{array}{c}\text { Kelembaban } \\
(\%)\end{array}$ & $\begin{array}{c}\text { Kecepatan } \\
\text { Angin } \\
(\mathbf{m} / \mathbf{s})\end{array}$ & $\begin{array}{c}\text { Arah } \\
\text { Angin }\end{array}$ & $\begin{array}{c}\text { Konsentrasi TSP } \\
\left(\mu \mathrm{g} / \mathbf{N m}^{3}\right)\end{array}$ \\
\hline 0 & 0 & 0 & 0 & - & 0 \\
\hline 5994 & 30,20 & 74,79 & 1,16 & $\mathrm{~S}$ & 81.3209 \\
\hline 6453 & 32,10 & 71,38 & 0,99 & $\mathrm{~S}$ & 87.5396 \\
\hline 0 & 0 & 0 & 0 & - & 0 \\
\hline 9971 & 30,44 & 71,76 & 1,58 & $\mathrm{~W}$ & 94.6290 \\
\hline 6077 & 31,21 & 71,19 & 1,16 & $\mathrm{SW}$ & 85.3913 \\
\hline 6187 & 29,50 & 75,74 & 1,59 & $\mathrm{SW}$ & 75.4707 \\
\hline 0 & 0 & 0 & 0 & - & 0 \\
\hline 6075 & 31,58 & 69,49 & 1,41 & $\mathrm{~S}$ & 85.4861 \\
\hline 6612 & 31,34 & 69,51 & 1,74 & $\mathrm{~S}$ & 87.3100 \\
\hline 8586 & 30,25 & 70,25 & 1,04 & $\mathrm{~W}$ & 90.8038 \\
\hline 10132 & 30,25 & 65,61 & 1,08 & $\mathrm{SW}$ & 98.3240 \\
\hline 5919 & 30,59 & 70,90 & 1,64 & $\mathrm{~S}$ & 79.5172 \\
\hline 0 & 0 & 0 & 0 & - & 0 \\
\hline
\end{tabular}

Berdasarkan ketiga waktu selama pengukuran didapatkan bahwa angin tidak memberikan dampak dan pengaruh yang dominan terhadap konsentrasi TSP. Hal ini dapat dilihat berdasarkan ketiga data pengukuran bahwa kecepatan angin dan arah angin tidak mempengaruhi besar atau kecilnya konsentrasi TSP. hal ini sesuai dengan penelitian Razif dan Prasasti (2006) yang dilakukan di Pusat Kota Surabaya dimana menjelaskan bahwa angin tidak memberikan pengaruh dominan terhadap penyebaran partikulat.

Tabel diatas merupakan tabel pengukuran pada sore hari yaitu pukul 16.00-18.00 WIB. Berdasarkan tabel tersebut didapatkan hasil bahwa volume kendaraan terbanyak terjadi pada tanggal 20 Agustus 2017 sedangkan yang volume kendaraan paling sedikit terjadi pada tanggal 21 Agustus 2017. Konsentrasi tertinggi terjadi pada tanggal 20 Agustus 2017, sedangkan konsentrasi terendah terjadi pada tanggal 15 Agustus 2017.

Berdasarkan ketiga tabel diatas, dapat dilihat bahwa konsentrasi TSP dipengaruhi oleh banyaknya volume kendaraan. Berdasarkan penelitian Maulana (2014) menyatakan bahwa semakin banyak kendaraan yang melintas maka akan semakin besar pula konsentrasi partikulat yang akan dihasilkan oleh kendaraan tersebut. Hal ini terbukti pada penelitian kali ini karena konsentrasi TSP tertinggi baik pada pagi, siang, maupun sore hari 
terjadi saat volume kendaraan terbanyak selama pengukuran. Konsentrasi TSP terendah juga demikian, saat volume kendaraan terjadi paling sedikit didapatkan hasil konsentrasi yang rendah. Namun hal tersebut terjadi hanya pada pagi dan siang hari, pada sore hari konsentrasi terendah tidak terjadi saat volume kendaraan tersedikit. Hal ini diakibatkan adanya pengaruh dari suhu dan kelembaban. Konsentrasi terendah selama pengukuran pada sore hari terjadi saat suhu paling rendah dan kelembaban paling tinggi selama pengukuran.

Suhu udara berpengaruh terhadap konsentrasi partikulat, ketika suhu udara meningkat maka konsentrasi partikulat juga akan meningkat. Suhu udara yang tinggi dapat mengakibatkan keadaan lingkungan menjadi panas dan kering sehingga polutan akan mudah terangkat dan melayang di udara (Cahyadi dkk, 2016). Sehingga ketika terjadi suhu udara yang rendah maka konsentrasi partikulat yang dihasilkan pun akan rendah. Selain itu juga terjadi karena faktor kelembaban dimana kelembaban memberikan pengaruh yang berbanding terbalik dengan suhu udara karena apabila suhu meningkat maka kelembaban udara akan berkurang. Hal itu juga berlaku sebaliknya, apabila suhu udara rendah maka kelembaban udara pun akan meningkat. Kondisi udara yang lembab dimana suhu udara turun akan menyebabkan terhalangnya radiasi matahari ke bumi karena terbentuknya awan di atmosfer dan membantu proses pengendapan bahan pencemar, sebab dengan keadaan udara yang lembab maka sejumlah partikel debu akan berikatan dengan air yang ada dalam udara dan membentuk partikel yang berukuran lebih besar sehingga akan lebih mudah untuk mengendap ke permukaan tanah (Wiraadiputri, 2012).

B. HASIL PENGUKURAN TOTAL SUSPENDED PARTICULATE (TSP) BERDASARKAN JENIS VEGETASI

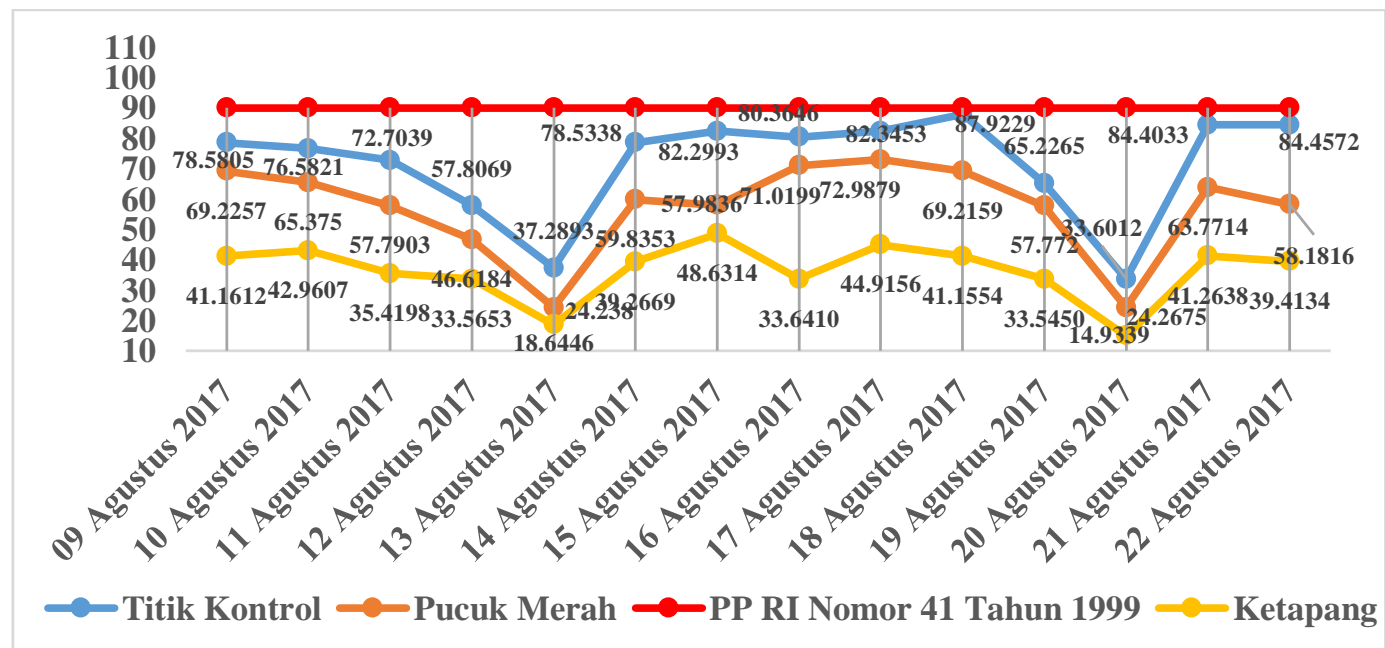

Gambar 2. Konsentrasi TSP pada Pukul 06.00-08.00 WIB

Bila dibandingkan dengan baku mutu dimana menurut Peraturan Pemerintah Nomor 41 Tahun 1999 tentang Pengendalian Pencemaran Udara konsentrasi maksimal TSP di udara adalah $90 \mu \mathrm{g} / \mathrm{Nm}^{3}$, maka untuk pengukuran pada pagi hari menunjukkan hasil bahwa selama waktu pengukuran konsentrasi TSP masih tergolong aman dalam 
rentang baku mutu. Volume kendaraan bermotor pada pengukuran pagi hari memang menunjukkan volume yang tinggi, tetapi suhu udara relatif rendah namun selama pengukuran berangsur-angsur meningkat. Kelembaban udara pun masih terbilang tinggi, cuaca pada pagi hari masih sangat lembab sehingga partikel yang ada berikatan dengan air yang ada di udara. Hal inilah yang menyebabkan konsentrasi TSP pada pagi hari masih dalam konsentrasi yang rendah. Begitu pula dengan hasil pengukuran dibelakang tanaman, baik itu pucuk merah maupun ketapang. Terjadi penurunan konsentrasi TSP menjadi lebih rendah dibandingkan konsentrasi pada titik kontrol.

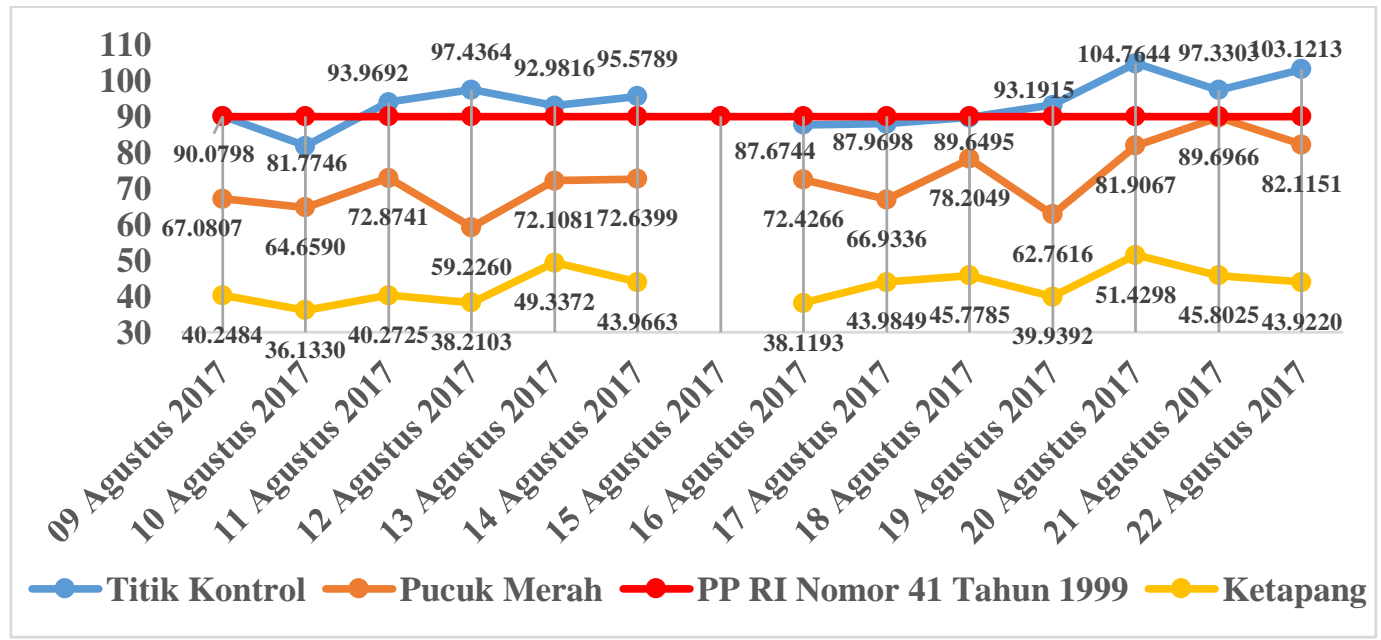

Gambar 3. Konsentrasi TSP pada Pukul $12.00-14.00$ WIB

Pengukuran pada siang hari menunjukkan angka yang tinggi bahkan dari sebagian besar hari pengukuran didapatkan hasil yang melewati standar baku mutu PP RI Nomor 41 Tahun 1999. Volume kendaraan bermotor yang melintas di SD Negeri 24 Pontianak Utara memang tidak menunjukkan angka yang tinggi seperti pada pagi hari, namun suhu udara pada siang hari tergolong tinggi sehingga kondisi udara menjadi panas dan kering. Hal ini pun mengakibatkan kelembaban udara yang rendah. Suhu udara yang tinggi tadi diakibatkan karena terdapat sinar matahari. Menurut Aprianti (2011), sinar matahari akan membantu meningkatkan konsentrasi partikulat karena sinar matahari akan menyebabkan terjadinya reaksi fotokimia antara gas kendaraan bermotor dengan sinar matahari yang akan membentuk partikulat sekunder. Banyaknya kandungan partikulat di udara tadi tidak tertangkap oleh butir-butir air diudara karena kondisi udara yang panas dan kering atau dalam kelembaban yang rendah. Namun konsentrasi yang melewati baku mutu tersebut dapat diturunkan konsentrasinya oleh vegetasi. Hal ini dapat dilihat bahwa pengukuran dibelakang tanaman pucuk merah dan ketapang terjadi penurunan konsentrasi dibandingkan dengan konsentrasi yang ada pada titik kontrol. 


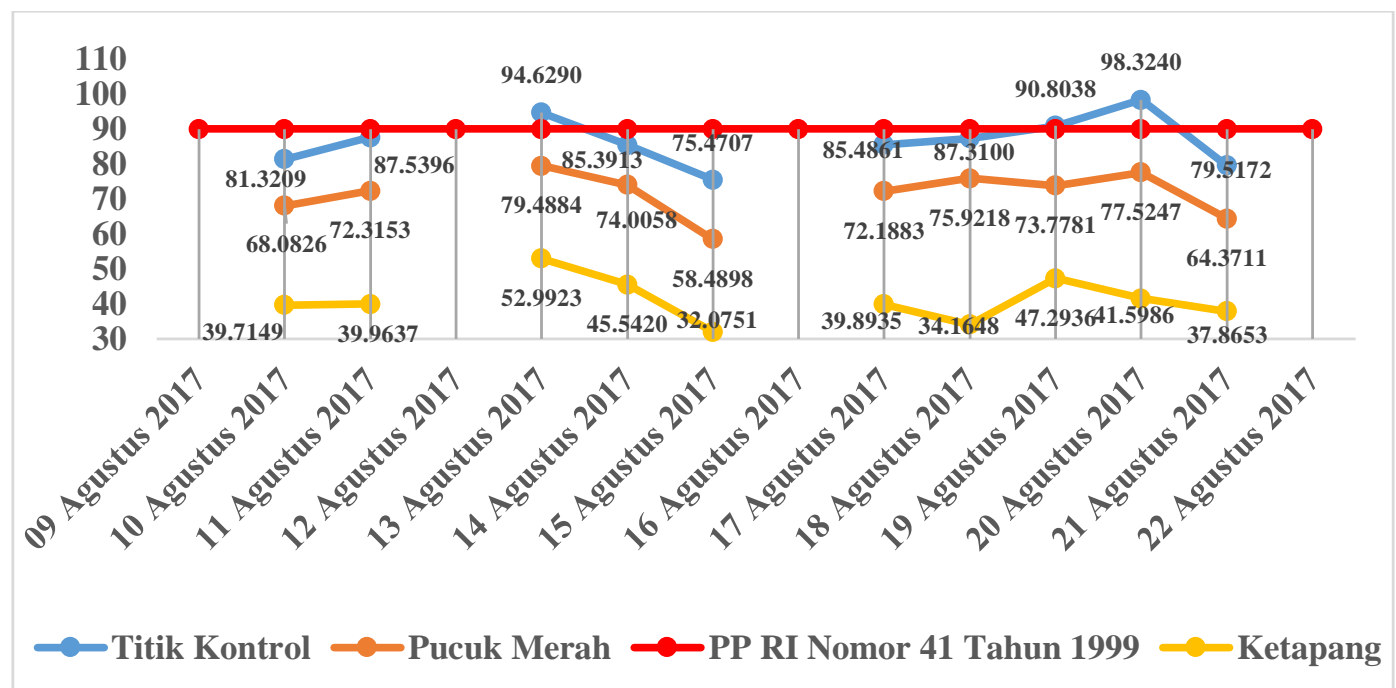

Gambar 4. Konsentrasi TSP pada Pukul 16.00-18.00 WIB

Pengukuran pada sore hari juga menunjukkan angka yang tinggi, namun tidak banyak terjadi konsentrasi pada hari pengukuran yang melewati standar baku mutu yaitu PP RI Nomor 41 Tahun 1999. Pengukuran yang melewati standar baku mutu hanya terjadi saat akhir pekan yaitu Sabtu dan Minggu karena pada hari libur volume kendaraan yang melintas di sore hari lebih tinggi dibanding hari biasanya. Volume kendaraan pada sore dan siang hari memang tidak jauh berbeda, namun perbedaan tingkat konsentrasi TSP lebih banyak disebabkan karena faktor meteorologis. Matahari bersinar selama pengukuran pada siang hari, namun pada sore hari matahari berangsur-angsur tenggelam. Hal ini menyebabkan suhu udara menjadi menurun dan kelembaban pun meningkat sehingga konsentrasi TSP tidak setinggi pada siang hari. Berdasarkan grafik diatas dapat dilihat bahwa konsentrasi pada belakang tanaman pucuk merah maupun ketapang dikategorikan aman bila dibandingkan dengan baku mutu. Menurut Peraturan Pemerintah Nomor 41 Tahun 1999 tentang Pengendalian Pencemaran Udara konsentrasi maksimal TSP di udara adalah $90 \mu \mathrm{g} / \mathrm{Nm}^{3}$. Semua hasil pengukuran TSP yang didapatkan membuktikan bahwa konsentrasi TSP berada dibawah baku mutu yang telah ditentukan. Terjadi penurunan konsentrasi TSP bila dibandingkan dengan titik kontrol, baik itu pada tanaman pucuk merah maupun ketapang.

\section{EFEKTIVITAS VEGETASI DALAM MENJERAP TOTAL SUSPENDED PARTICULATE (TSP)}

Efektivitas vegetasi dalam menjerap TSP didapatkan dengan rumus (Resiana, 2014):

$E=\frac{C_{0}-C}{C_{0}} \times 100 \%$

Dimana: $\mathrm{E}$ = Efektivitas (\%)

$\mathrm{C}_{0}=$ Konsentrasi TSP pada titik kontrol $\left(\mu \mathrm{g} / \mathrm{Nm}^{3}\right)$

$C=$ Konsentrasi TSP hasil pengukuran pada belakang vegetasi $\left(\mu \mathrm{g} / \mathrm{Nm}^{3}\right)$ 
Tabel 4. Efektivitas Vegetasi dalam Menjerap TSP

\begin{tabular}{cccccc}
\hline \multicolumn{7}{c}{ Efektivitas (\%) } \\
\hline $\mathbf{0 6 . 0 0 - 0 8 . 0 0}$ & $\mathbf{1 2 . 0 0 - 1 4 . 0 0}$ & $\mathbf{1 6 . 0 0 - 1 8 . 0 0}$ & $\mathbf{0 6 . 0 0 - 0 8 . 0 0}$ & $\mathbf{1 2 . 0 0 - 1 4 . 0 0}$ & $\mathbf{1 6 . 0 0 ~ - ~ 1 8 . 0 0 ~}$ \\
\hline 11.90 & 25.53 & 0.00 & 47.62 & 55.32 & 0.00 \\
\hline 14.63 & 20.93 & 16.28 & 43.90 & 55.81 & 51.16 \\
\hline 20.51 & 22.45 & 17.39 & 51.28 & 57.14 & 54.35 \\
\hline 19.35 & 39.22 & 0.00 & 41.94 & 50.78 & 0.00 \\
\hline 35.00 & 22.45 & 16.00 & 50.00 & 46.94 & 44.00 \\
\hline 23.81 & 24.00 & 13.33 & 50.00 & 54.00 & 46.67 \\
\hline 29.55 & 0.00 & 22.50 & 40.91 & 0.00 & 57.50 \\
\hline 11.63 & 17.39 & 0.00 & 58.14 & 56.52 & 0.00 \\
\hline 11.36 & 23.91 & 15.56 & 45.45 & 50.00 & 53.33 \\
\hline 21.28 & 12.77 & 13.04 & 53.19 & 48.94 & 60.87 \\
\hline 11.43 & 32.65 & 18.75 & 48.57 & 57.14 & 47.92 \\
\hline 27.78 & 21.82 & 21.15 & 55.56 & 50.91 & 57.69 \\
\hline 24.44 & 7.84 & 19.05 & 51.11 & 52.94 & 52.38 \\
\hline 31.11 & 20.37 & 0.00 & 53.33 & 57.41 & 0.00 \\
\hline $\mathbf{2 0 . 9 9 \%}$ & $\mathbf{2 2 . 4 1 \%}$ & $\mathbf{1 7 . 3 1 \%}$ & $\mathbf{4 9 . 3 6 \%}$ & $\mathbf{5 3 . 3 7 \%}$ & $\mathbf{5 2 . 5 9 \%}$ \\
\hline
\end{tabular}

Berdasarkan tabel diatas, dapat dilihat bahwa Pohon Ketapang memiliki efektivitas lebih besar dibandingkan dengan Pucuk Merah. Santoso (2011) menyatakan bahwa tanaman yang memiliki kemampuan tinggi menjerap dan menyerap polutan adalah tanaman yang memiliki tajuk rimbun, tidak gugur daun, dan tanamannya tinggi. Sedangkan Al-Hakim (2014) mengatakan bahwa pohon yang kurang sesuai dalam menjerap polutan memiliki beberapa ciri fisik yang terpenuhi namun kurang baik pada ciri fisik yang lain seperti struktur permukaan daun yang halus, bentuk daun yang kecil, tajuk yang tidak padat dan renggang, tekstur kulit batang pohon yang halus, serta kepadatan ranting yang renggang.

Kriteria penjerap yang baik merupakan kriteria yang dimiliki oleh pohon Ketapang. Daun pohon Ketapang yang menjarum dan melebar lebih efektif dalam menjerap partikel karena memiliki luas permukaan daun yang lebih besar. Selain itu pohon Ketapang memiliki massa tajuk yang massif dan rapat serta ranting dan batang yang rapat dan berpermukaan kasar sehingga dapat menjerap partikel lebih besar dan efektif. Hal ini sangat menunjang dalam kemampuannya untuk mengadsorbsi (menjerap) partikel debu yang terdapat di udara. Bila dibandingkan dengan Pucuk Merah, Pucuk Merah memiliki daun yang tipis dan kecil. Permukaan daun Pucuk Merah halus dan mengkilap. Selain itu ranting dan tajuk yang dimiliki oleh Pucuk Merah tidak terlalu padat seperti Ketapang. Pohon Ketapang memiliki volume kerimbunan yang lebih besar yaitu $155,83 \mathrm{~m}^{3}$ bila dibandingkan dengan Pucuk Merah yaitu $2,56 \mathrm{~m}^{3}$. Hal inilah yang menyebabkan Pucuk Merah tidak terlalu efektif dalam menjerap partikel. 


\section{KESIMPULAN}

Berdasarkan penelitian yang telah dilakukan, maka dapat disimpulkan beberapa hal sebagai berikut:

- Konsentrasi Total Suspended Particulate (TSP) di kawasan SD Negeri 24 Pontianak Utara memiliki nilai konsentrasi tertinggi pada siang hari yaitu $104,7644 \mu \mathrm{g} / \mathrm{Nm}^{3}$ dan berada diatas baku mutu PP RI Nomor 41 Tahun 1999 yaitu $90 \mu \mathrm{g} / \mathrm{Nm}^{3}$.

- Efektivitas penjerapan tertinggi adalah 53,37\% yang merupakan efektivitas pengukuran pada siang hari yang dijerap oleh pohon Ketapang.

\section{UCAPAN TERIMA KASIH}

Terima kasih kepada dosen pembimbing skripsi, Ibu Dian Rahayu Jati dan Ibu Sarma Siahaan serta dosen penguji skripsi, Ibu Yulisa Fitrianingsih dan Ibu Jumiati, Pihak SD Negeri 24 Pontianak Utara, serta semua pihak yang terlibat dan membantu penulis selama proses pengerjaan penelitian yang tidak dapat diucapkan satu persatu.

\section{DAFTAR PUSTAKA}

Al-Hakim, A.H. 2014. Evaluasi Efektivitas Tanaman dalam Mereduksi Polusi Berdasarkan Karakter Fisik Pohon pada Jalur Hijau Jalan Pajajaran Bogor. Skripsi. Bogor: Fakultas Pertanian Institut Pertanian Bogor.

Aprianti, D. 2011. Analisis Pengaruh Tingkat Volume Lalu Lintas Kendaraan di Pintu Tol terhadap Tingkat Konsentrasi Total Suspended Particulate (TSP) dan Pengukuran Konsentrasi Timbal di Udara Ambien (Studi Kasus: Pintu Tol Cililitan 2, Bulan Januari-Februari 2011). Skripsi. Depok: Teknik Lingkungan Universitas Indonesia.

Cahyadi, W.; Achmad, B.; Suhartono, E.; dan Razie, F. 2016. Pengaruh Faktor Meteorologis dan Konsentrasi Partikulat (PM10) terhadap Kejadian Infeksi Saluran Pernapasan Akut (ISPA) (Studi Kasus Kecamatan Banjarbaru Selatan, Kota Banjarbaru Tahun 2014-2015). Jurnal. EnviroScienteae Vol. 12 No. 3.

Maulana, R.; Fitrianingsih, Y.; dan Sulandari, E. 2014. Analisis Pengaruh Tingkat Volume dan Jenis Kendaraan Terhadap Konsentrasi Particulate Matter (PM10) (Studi Kasus: JI. Sutan Syahrir, JI. Ahmad Yani dan JI. Kom. Yos. Sudarso Kota Pontianak. Jurnal. Teknik Lingkungan Universitas Tanjungpura Pontianak.

Razif, M. dan Prasasti, S.I. 2006. Pemetaan Tingkat Konsentrasi Partikulat Akibat Transportasi di Wilayah Surabaya Pusat. Jurnal Purifikasi, 7: 13-18.

Resiana, F. 2014. Efektivitas Penghalang Vegetasi Sebagai Peredam Kebisingan Lalu Lintas di Kawasan Pendidikan Jalan Ahmad Yani Pontianak. Skripsi. Pontianak: Teknik Lingkungan Universitas Tanjungpura.

Santoso, S.N. 2011. Penggunaan Tumbuhan sebagai Pereduksi Pencemaran Udara. Jurnal. Jurusan Teknik Lingkungan FTSP ITS.

Wiraadiputri, P.A. 2012. Studi Perbandingan Konsentrasi Total Suspended Particulate (TSP) Di Dalam dan Di Luar Ruang Kelas (Studi Kasus: Sekolah Dasar Negeri Pondokcina 1 Depok). Skripsi. Depok: Teknik Lingkungan Universitas Indonesia. 